\title{
Introduction to The Silent Majority: Invertebrates in Human-Animal Studies
}

\author{
Lisa Jean Moore \\ State University of New York, Purchase, NY \\ lisa-jean.moore@purchase.edu \\ Rhoda M. Wilkie \\ School of Social Science, University of Aberdeen, Scotland, UK \\ r.m.wilkie@abdn.ac.uk
}

\begin{abstract}
This essay introduces the rationale for and the contributions to the special issue The Silent Majority: Invertebrates in Human-Animal Studies.
\end{abstract}

\section{Keywords}

invertebrates - women - Lamarck - bias

The term invertebrate, generally attributed to French naturalist and early proponent of theories of evolution Jean-Baptiste Lamarck, emerged in the early 180os. An invertebrate is a nonhuman animal who does not have a backbone or spinal column. In categorizing and classifying these animals, Lamarck (Packard, 1901) reveals a reverence for invertebrates,

we should chiefly devote our attention to the invertebrate animals, because their enormous multiplicity in nature, the singular diversity of their systems of organization, and of their means of multiplication ... show us, much better than the higher animals, the true course of nature, and the means which she has used and which she still unceasingly employs to give existence to all the living bodies of which we have knowledge. (p. 41) 
Yet despite their noteworthy abundance, diversity and proliferation, invertebrates are defined by their lack. Defining something by what it lacks is not uncommon in classification-particularly in dichotomies. The category of woman, or the feminine, for example, especially in certain strands of psychoanalysis, is characterized by a lack - a lack of the actual biological penis or the symbolic phallus. ${ }^{1}$ In both cases, we identify this lack only in reference to some quality of the counterpart. In other words, vertebrates or men occupy the intact category and invertebrates and women by comparison are deficient.

Invertebrates can also be described as lacking strength, firmness or consistency, whereas women may be referred to as weak or fickle. Invertebrates and women alike are "spineless." Therefore, in the case of dichotomous or binary thinking, the vertebrate/invertebrate or man/woman classification establishes mutually exclusive categories based in part on anatomical differences that imply ranking. Social preferences embedded within these definitions accrete into the very ways we co-produce invertebrates and women as meaningful subjects and objects.

We argue that just as male bias structures the production of knowledge (Harding, 1991), likewise vertebrate bias structures our thoughts—it influences human decisions on what we value and what we think is worth knowing or investigating. This special issue attends to the "silent majority" of invertebrate animals (Moore, 2017, p. 166) and affords a timely opportunity to critically reflect on what is meant by "animal" in human-animal studies/scholarship.

For example, according to the Center for Biological Diversity (n.d.), invertebrates make up at least " $97 \%$ of all animal species on earth." Yet, as the first essay by Wilkie, Moore, and Molloy shows, the majority of articles in two pioneering human-animal studies journals have not studied invertebrate animals. This apparent "bias against animals without backbones" might reflect what one entomologist has called "institutional vertebratism" in the field (Leather, 2009, pp. 413-414). Furthermore, consider insects, the largest percentage of world's animals (May, 1988). A recent study on entomophagy highlights the ambiguous status of edible insects when a respondent noted, they "are animals, but not animals like the real animals" (House, 2016, p. 55).

This special issue on The Silent Majority includes an interdisciplinary array of scholarly engagement with invertebrates. The lead essay by Wilkie et al. reports on a scoping study of Anthrozoös and Society \& Animals to confirm claims of a vertebrate bias in human-animal studies scholarship. Next Shen considers multisensorial artistic practice in collaborations between humans and ants

1 Philosophical analysis reveals that women being equating with lack (of intellect, of a penis) dates back to Aristotle (see Sparshott, 1983). 
to explore the generative capacities of invertebrate aesthetics. Art Historian Cortés Zulueta's media content analysis examines how hermit crabs have recently become poster animals in the global waste crisis, specifically the "plastic apocalypse." Ancient Historian Evans and Biologist Weinstein continue with a detailed account of ancient Egyptians' atypical relationship with invertebrates to show how they did not distance themselves from such animals but celebrated their myriad forms. Outdoor Recreation and Tourism scholars Lemelin, Boileau, and Russell consider the contemporary allure of arthropods in entomotourism, while geographer Bear, through interview data, interprets how edible-insect farmers frame the death of insects. Finally, Lindsay, a Sociology doctoral student, rounds off the special issue with a comparative book review on two recent books about bees.

We intend this issue to be generative to the growth of invertebrate representation in human-animal scholarship. However, we want to be clear that our gesturing away from vertebrate species does not mean we wish to create a firm boundary but rather we are hoping for an inclusive consideration of all animals in our field. Thanks to all the reviewers, and to Susan McHugh, Nik Taylor, Ken Shapiro, and Ann Casper for making this issue possible.

\section{References}

Center for Biological Diversity. (n.d.). Invertebrates. Retrieved June 9, 2019, from https://www.biologicaldiversity.org/species/invertebrates/.

Harding, S. (1991). Whose knowledge, whose science: Thinking from women's lives. Ithaca: Cornell University Press.

House, J. (2016). Consumer acceptance of insect-based foods in the Netherlands: Academic and commercial implications. Appetite, 107, 47-58. DoI: 10.1016/j.appet .2016 .07 .023 .

Leather, S. (2009). Institutional vertebratism threatens UK food security. Trends in Ecology and Evolution, 24(8), 413-414.

May, R. M. (1988). How many species are there on earth? Science, 241(4872), 1441-1449.

Moore, L. J. (2017). Catch and release: The enduring yet vulnerable horseshoe crab. New York: New York University Press.

Packard, A. S. (1901). Lamarck, the founder of evolution. London, UK: Longmans, Green and Company.

Sparshott, F. (1983). Aristotle on women. The Society for Ancient Greek Philosophy Newsletter, 107, Retrieved May 3, 2019, from https://orb.binghamton.edu/sagp/107. 